\title{
AC-130H Gunship Armor Upgrade Project
}

Part I: Ballistic Test Methods and Testing Configurations (Uncl.)

Thomas E. Shell

Richard L. Landingham

University of California

Lawrence Livermore National Laboratory

Livermore, CA 
Content

I. Types of Targets

A. Soft armor

B. Hard armor

II. Adhesives

III Projectile Descriptions

IV. Armor Testing Procedure

A. Soft armor

B. Hard armor

Appendix A. Ballistic Capability at LLNL

$-1-$ 


\section{Types of Targets}

Four different types of targets were tested in this program. These targets were broken down into two groups of either "soft" or "hard" armor systems.

\section{A. Soft Armor (Blankets of woven fibers)}

The soft armor was blanket type ballistic material either from the existing gunship or two new type armor blankets supplied by Allied Signal.

The blanket* from the existing gunship was multi-layer Kevlar faced with a woven fiberglass covering. The blanket was slightly " $L$ " shaped and was nominally $78 "$ x $38 "$.

The new soft armor blankets were Spectra 900 and 1000 at 41 layers of 650 denier and 40 layers of 400 denier respectively. Both blankets were Kevlar faced(0.017" thick) to meet fire retardant specifications (M:1 Spec A$46103 \mathrm{Rev} . \mathrm{C}$ ). These new soft armor blankets were rectangular and nominally $70^{\prime \prime} \times 52 "$.

\section{B. ${ }^{*}$ Hard Armor - (Ceramics or Cermets with Polymer Composite Back-up plates)}

The hard armor targets were either from the existing gunship system or new hard armor targets consisting of aluminum/boron carbide cermet tile bonded to Spectra 1000 back plate from Allied Signal.

The existing gunship armor panels* were silicon carbide tiles bonded to a woven roving back plate with a thin layer of roving over the face of the tiles. These panels were rectangular and nominally $30^{\prime \prime} \times 17 "$.

The new hard armor targets were assembled at LLNL. These targets consisted of the aluminum cermet tiles bonded to Spectra Shield 1000 (SST) unidirectional prepreg. We also received Spectra 900 (SSV) woven (vinylester prepreg) back plates. The following numbering system was attached to these unidirectional panels which were all 12 " $\times 12$ " square.

$\begin{array}{lll}\# 1004 & \text { SST } & 1,0 \mathrm{PSF} \\ \# 1005 & \text { SST } & 1.5 \mathrm{PSF} \\ \# 1006 & \text { SST } & 2.0 \mathrm{PSF} \\ \# 1007 & \text { SSV } & 1.0 \mathrm{PSF} \\ \# 1008 & \text { SSV } & 1.5 \mathrm{PSF} \\ \# 1009 & \text { SSV } & \text { 2.0 PSF }\end{array}$

* $P N$ \#529-101-218-1 Ser \#15

${ }^{* *} P N$ \#529-101-015 Ser \#166-170 
These panels were obtained from Composiflex Company and were covered on both sides with a fire retarding glass epoxy layer (0.012" thick) to meet MIL Spec A46103 Rev. C.

The aluminum cermet tiles (6" by $6 "$ ) were received from Greenleaf Corporation with three different thicknesses. These tiles were bonded to the Spectra panels as discussed in the following section on adhesives.

\section{Adhesives}

As the hard targets were cermet tile bonded to the Spectra shield back plate, adhesive bonds play an important role in the success of this project. Several different bonding systems were considered prior to the actual ballistic testing.

Preliminary panels supplied by Allied Signal were without the Kevlar fire retardant surfaces. Simple peel tests were conducted on these panels with two types of polymer systems. Urethane and epoxy were tried with and without primed substrate surfaces. Very little success was achieved with either due to the weak bonding of the substrates fibers/matrix system. In all cases, debonding occurred at the first fiber layer, leaving the first fiber layer attached to the peel fixture. Conap TU-89 Urethane and Hardman Quickset Epoxy were used for these tests, with a Conap A6 primer used to prime the panels on some of the tests. Typically, the Quickset Epoxy had the least strength and the urethane the most strength when tested on other substrates. We found that both performed similarly on the Spectra shield panels, with no real difference due to the first layer debond problems.

Subsequently, Spectra shield panels were supplied with the Kevlar facing. We again tried the peel tests and this time adding a third bonding system. This third system was Pro-Seal 890-A-2(*) polysulfide sealant. Bonds were made using all three systems, bonded directly to the Kevlar facing with no surface preparation. All three bonding systems worked very well. The polysulfide sealant was chosen due to previous field use for this type application.

Cermet tiles were bonded to the Spectra shield back plates with polysulfide anc cured 24 hours at $60^{\circ} \mathrm{C}$ for ballistic tests. At no time during the ballistic testing did the bonds fail; however, the bond between the Kevlar and Spectra generally did fail under ballistic impact. This particular bond failure could be troublesome in field applications. More effort needs to be made to improve this bond between the Spectra and Kevlar or the newly developed fire retardant matrix composite from Allied Signal needs to be evaluated for this applicatior.

(*) MIL-S-8802RE Amend 3 Type II Class A-2 


\section{Prolectile Description and Armor Testing Procedures}

Ballistic test results are generally described as having a " $\mathrm{V}_{50}$ " or "ballistic limit" value. These values were developed to quantify the results of extensive ballistic tests, usually against monolithic metal targets. The term " $V_{50}$ " indicates $50 \%$ of the projectiles perforate the target and $50 \%$ do not perfora!e at any given velocity. The term "ballistic limit" or $V_{B L}$ is applied accordingly to targets where the projectile just breaks through the back plate. Usually, these terms apply to a large amount of targets and are used for a quantifying armor performance.

Due to budget and time constraints, we could not do the massive amount of shots needed to establish these values. However, for these screening tests, establishing an experimental limit velocity gave us trends in the data as well as materials performance for armor design purposes.

Between 3 and 8 shots per target series were performed depending on confidence level after each test. One might assume that confidence level was high the fewer targets tested in any one series and conversely, the more targets tested the lower the confidence level to establish the series experimental limit velocity. Experimental limit velocity is defined as the velocity at which perforation: causes no damage behind the target. If the projectile perforated the target, but made no marks on the aluminum witness plate, then the experimental limit velocity was established and one to two more shots were done at that velocity to verify this value.

In our testing of the soft and hard armors for this program, the soft armors had the least confidence level, thereby demanding the larger amount of shots to establish experimental limit velocity.

\section{Projectile Description}

All projectiles used in our testing were either $207 \mathrm{gr}$. or $170 \mathrm{gr}, 50$ caliber fragment simulating projectiles (FSP)*. These projectiles were obtained from HP White Lab, Inc. Figure 1 shows these projectiles mounted in the 50 cal. brass and in both 207 and $170 \mathrm{gr}$ configuration. The $170 \mathrm{gr}$ configuration had the same dimensions as the $207 \mathrm{gr}$, but drilled out from the back to reduce the weight to $170 \mathrm{gr}$.

Powder charges ranged from 6-10 grams of IMR 4350 which is a DuPont double based smokeless powder.

"MIL-P-46593 

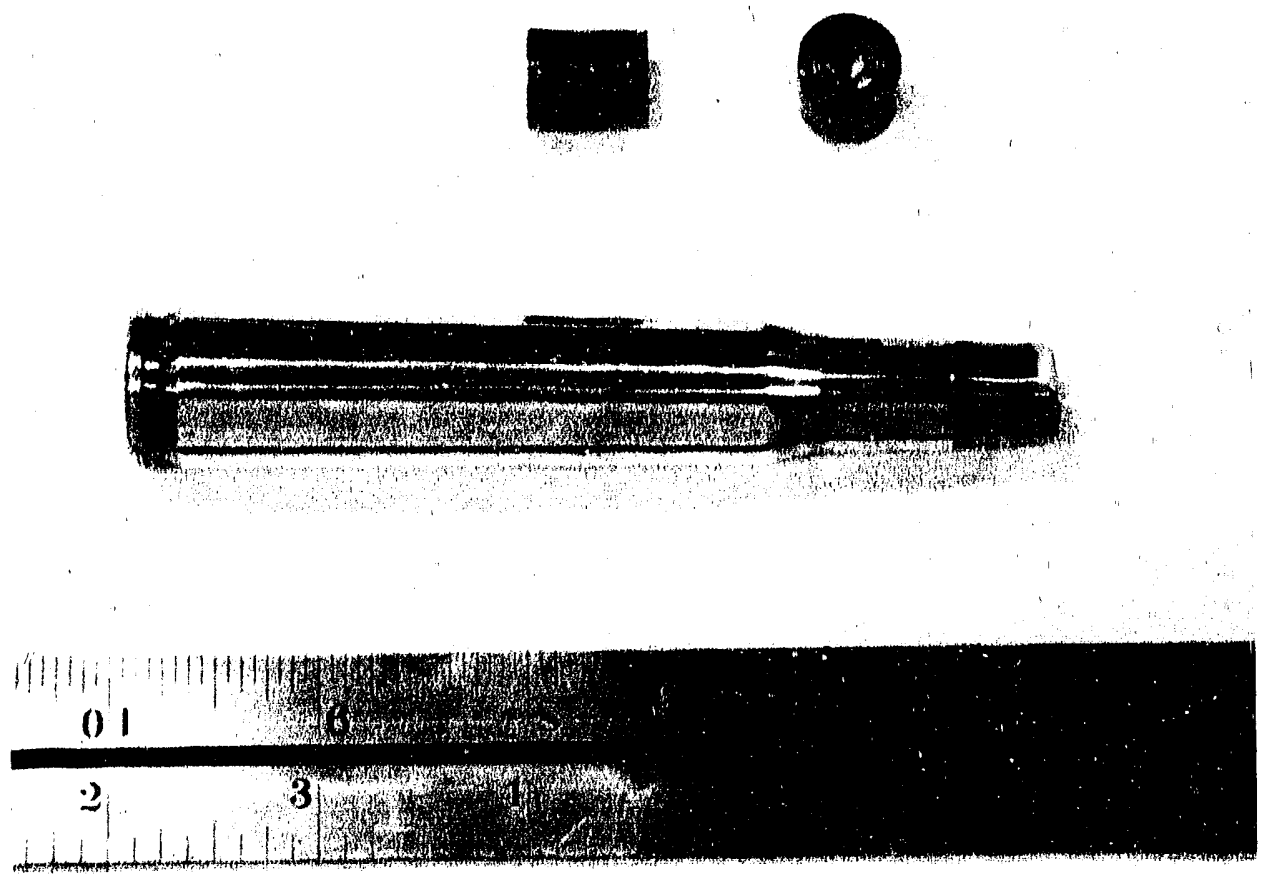

Figure 1

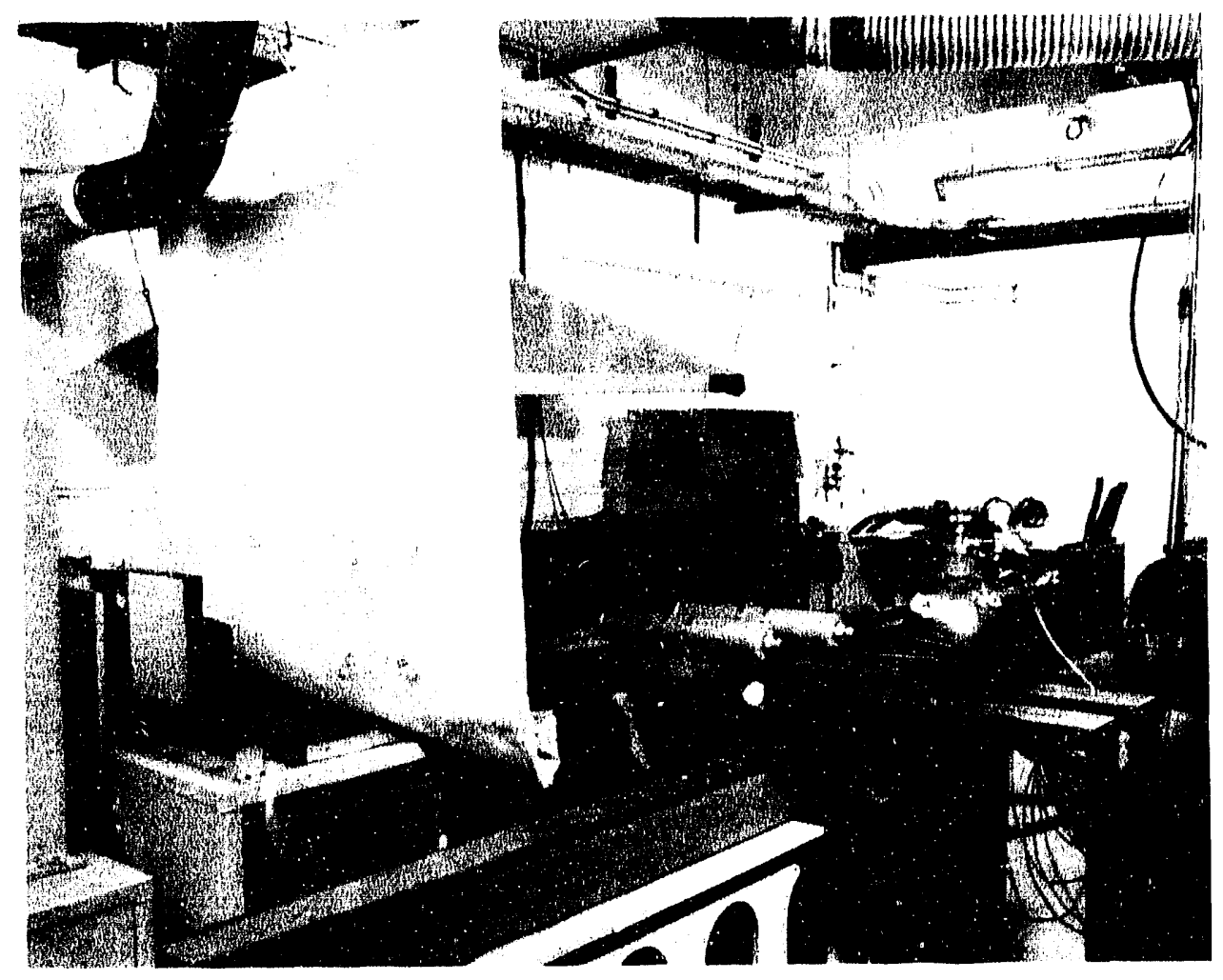

Figure 2 


\section{Armor Testing Procedures - Soft Armors}

\section{A. Soft Armor}

To test the soft armor, the blankets were hung from an overhead beam approx. 5 feet above the shot table (Fig. 2). The blankets were either ' $C$ ' clamped or hung from the bar using their own integral fasteners. Impact areas were at leasi 8" from any edge and 8"-10" from other impact areas (See Fig. 1A in appendix). Experimental limit velocities were established for both the $207 \mathrm{gr}$. and $170 \mathrm{gr}$. projectiles. Flash $\mathrm{X}$-rays were used to determine velocity on all shots.

Impact excursion of the soft armors was thought to be a factor in the experimental limit velocity. A simple method was devised to measure this excursion on both the hard and soft armor tests. This method will be described in the hard armor testing discussion in the following section.

\section{B. Hard Armors}

Hard armor targets received from the existing gunship stock were mounted in the shot-tank with clamps to simulate actual mountings used in the gunship. This allowed full back piate excursion of the panel.

Two of the panels were used in this testing, with at least 6 shots made on each panel. All shots were done at least 6" from any edge or 6" from any impact area. Impact excursion of the woven roving back plate was minimal. Experimental limit velocities were established for these panels.

Hard armor targets assembled at LLNL, were mounted in the shot can as shown in Fig. 3. The first targets were supported on opposite sides only. This led to large excursions of the back plate and in most cases the tarset was pushed almost through the clamping arrangement. After addition of a 1" frame to support all four edges, the target stability was improved and excursion data improved.

The excursion data was obtained using a simple arrangement of Q-tips and styrofoam layed out so the Q-tips were touching the back of the target. Qtips were placed in a square matrix on 1 " $\times 1$ " centers flush with the back of the styrofoam. If the back of the target did bow upon impact, this excursion was measured by noting the new positions of the $Q$-tips in relation to the styrofoam. A typical setup for hard armor is shown in Fig. 3 and in Fig. 4.

Some of these hard armor targets were tested using a simulated AC$130 \mathrm{H}$ floor panel behind the target to see if the floor panel either helped or hurt the ballistic performance of the armor. 2024-T6 alum. sheet (.080" thk). and extruded aluminum channel was used to simulate the floor panels. The channel was tack welded to the 2024-T6 with welds 1/2" long on each side of the channel and 1 " between welds. A typical test setup using the floor panels is shown in Fig. 5 with a standoff of .750" between the armor and floor panel as designed into existing gunships. 


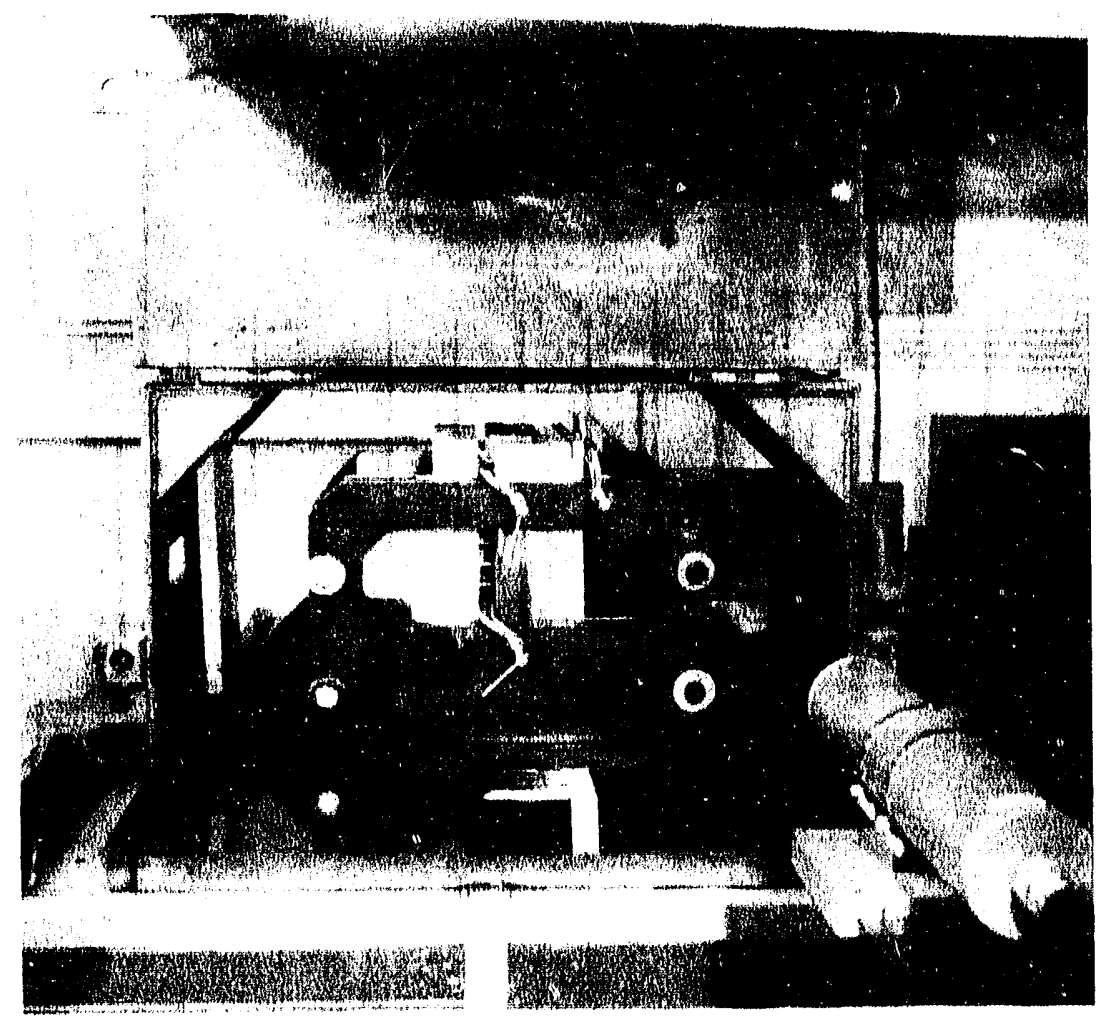

Figure 3

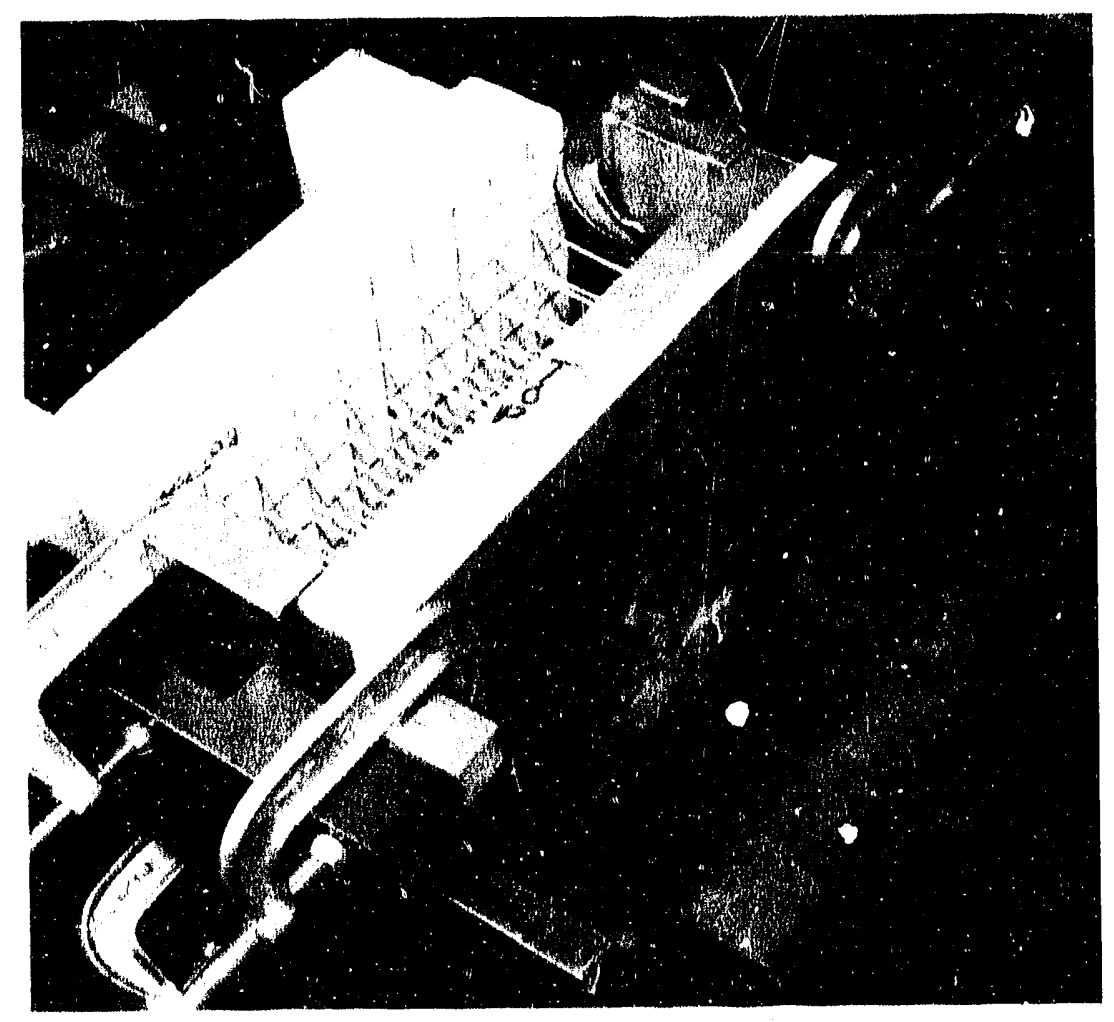

Figure 4 


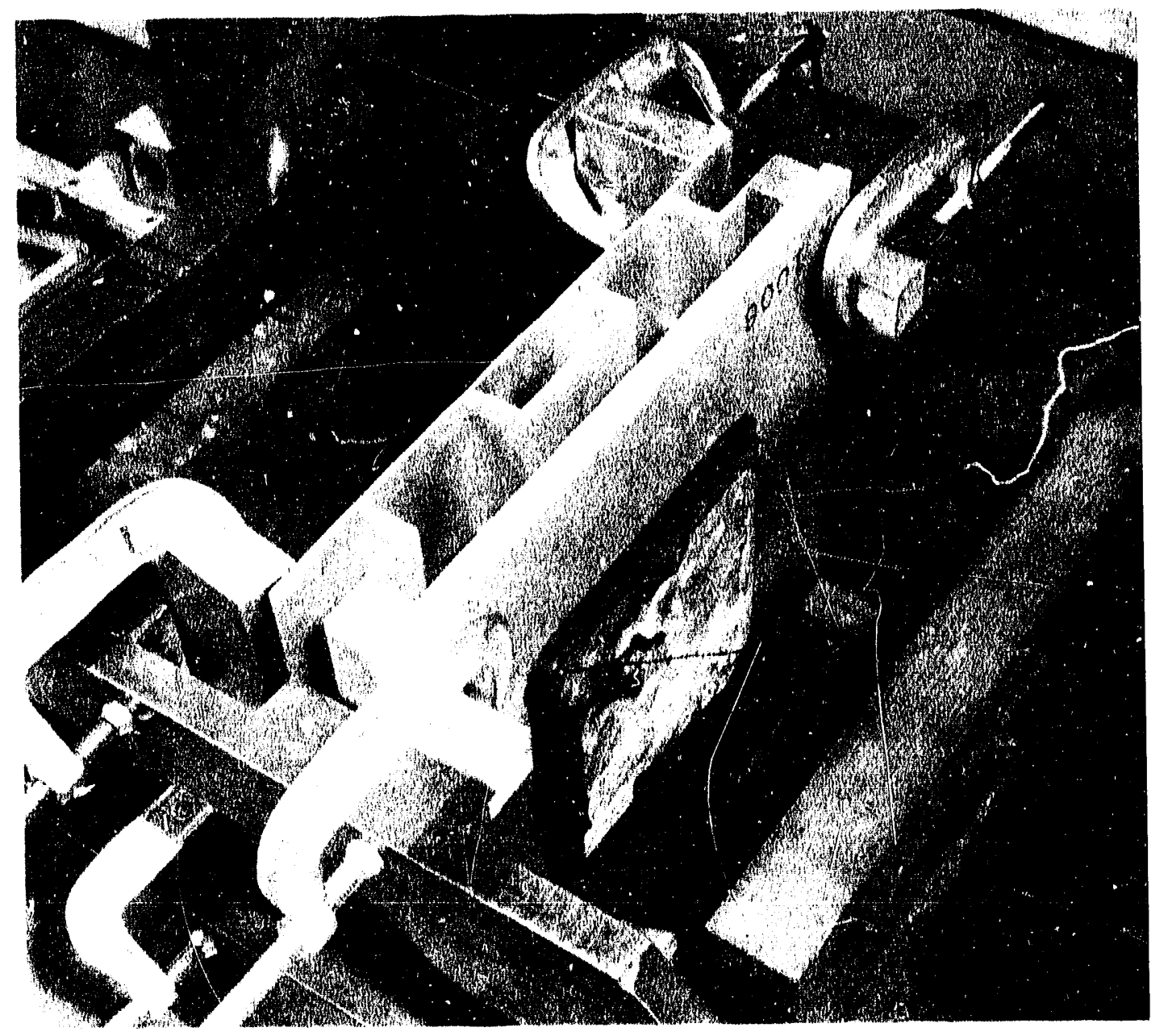

Figure 5 


\section{APPENDIX A \\ Ballistic Capability at LLNL}

\section{Eacillity Qverview}

At the present time, we have the ballistic testing capability to test a wide variety of targets and projectiles. These capabilities are listed. The most commonly used systems ilsted with an *. They will be detailed in this appendix. A detalled section on dlagnostics is also included.

\begin{tabular}{|c|c|}
\hline $\begin{array}{l}\text { 10-cal./.257 Weatherby Mag. } \\
.221 \text { Remington "Fireball" } \\
\text { 5.56-mm NATO } \\
\text { 7.62-mm NATO } \\
.300 \text { Winchester Mag. } \\
.350 \text { Remington Mag. } \\
\text {.303 British } \\
.458 \text { Winchester African Mag. } \\
.460 \text { Weatherby Mag. } \\
\text { 30-06* } \\
.50-\text { cal. BMG* }^{\star} \text { 14.5-mm Frankfort Arsenal } \\
\text { 23/37-mm 1/4 scale* }\end{array}$ & $\begin{array}{l}\text { Smoothbore } \\
\text { Rifled } \\
\text { Rifled } \\
\text { Rifled } \\
\text { Smoothbore } \\
\text { Rifled } \\
\text { Rifled } \\
\text { Smoothbore } \\
\text { Smoothbore } \\
\text { Rifled/smoothbore } \\
\text { Rifled/smoothbore } \\
\text { Rifled/smoothbore } \\
\text { Rifled/smoothbore }\end{array}$ \\
\hline
\end{tabular}

We have, at the present, four gun systems that are fuly operational at any one time. Figure A1 shows all light guns except the 1/4-scale. As we will see later, some of the guns have universal breech and firing mechanisms. The first gun system to be described will be the 30-06.

30-06

This gun consists of a barreled action with a 0.303 -in.-diam. smooth bore 24 in. long. The barrel is made by G. R. Douglas Co. and is mounted to a single-shot boltaction Mauser-style breech made by Fabrique National of Herstal, Belgium. This gun is on a fixed mount, permanently affixed to an aluminum table and the trigger is 300 volt DC solenoid-actuated.

50-cal. BMG (second from left in Fig. A1)

This is a single-shot gun on a Universal Bond receiver. It has an interchangeable barrel system, and is currently avaliable with a 36-in. rifled or 60-in. smoothbore barrel. Since the receiver is universal, barrels from .22-cal. to 1?-ga. shotguns can be fitted. Currently, wie have a 30-06 rifled barrel that can be used for this system. The action is a falling block, single action, and 300-volt DC solenoidactuated. 


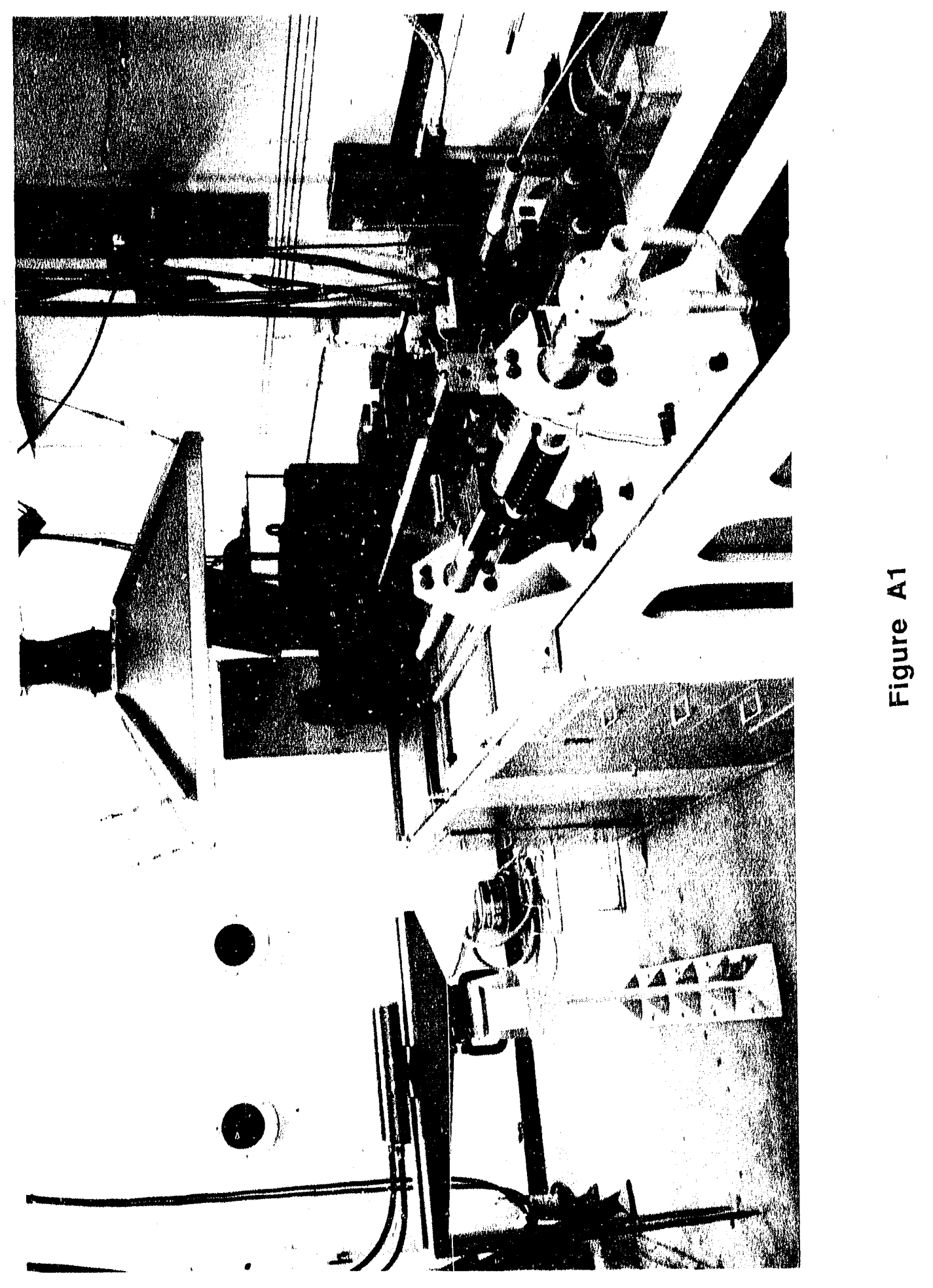




\section{5-mm (Fig. A2)}

This is a single-shot gun using a Frankfort Arsenal designed breech. There are presently two barrels and two breeches for this system. One barrel is smoothbore, 60 in. long, and the other is rifled, $60 \mathrm{ln}$. long. Both barrels are chambered for the US M103 20-mm case, which nearly duplicates the powder capacity of the Soviet 14.5$\mathrm{mm}$ heavy-machine-gun shell casing. The chamber has a transition cone of approximately $30^{\circ}$ to allow for the mismatch between projectile and case. The drawings for this gun are FMC \#4197197 and LLNL Drawing \#AAA-84-11 \$100-00 (assembly).

One of the breeches is electric (Frankfort Arsenal) and one percussion-type (LLNL design). The percussion breech uses a standard .50-cal. primer with appropriate bushing for size and is solenoid-fired.

The 14.5-mm gun system can be fired through a LLNL-designed silencer that has been shown to be quite effective for reducing the muzzle blast and assoclated acoustic problems. The inner tube is slotted ard is fitted to the bore i.d. of the $14.5-\mathrm{mm}$ with a retaining collar. The material used for the sound-deadening is an aluminum foam, cut into doughnuts and fitted between the inner tube and outer jacket.

\section{3/37-mm 1/4-scale gun (not shown)}

This is a single-shot screw-type breech designed by Van Dyke et al. It is based on his work on the $40-\mathrm{mm}$ gun that is now at Los Alamos National Laboratory. The gun is chambered for the $37-\mathrm{mm}$ anti-aircraft cartridge, but has a nominal bore. This bore size is attained by use of a transition cone ahead of the chamber.

The ballistics of the gun basically duplicate those of a similar gun located at the Ballistic Research Laboratory, Aberdeen, Maryland. It is scaled to produce $1 / 4$ the terminal effects produced by a heavy metal projectile ( $W$ or $U$ alloy) fired against a rolled-homogeneous-armor target; that is, $1 / 4$ the effect against a full-scale target by an A.P.F.S.D.S. round fired from an M-68 105-mm main battle tank gun. Our 1/4-scale gun is equipped with four barrels. Two have recently been rebored to $24.5 \mathrm{~mm}$. This gun is fired by solenoid as described above.

This gun is also equipped with a light gas breech for launching projectiles at lower than normal velocities. It has the advantage of very precise velocities. With the single-stage gas breech, 150-gram projectlles are launched at $0.05-0.08 \mathrm{~km} / \mathrm{s}$.

All 1/4-in.-scale shots are fired into a two-part vacuum chamber. The first part consists of an oblong square-cross-section box and sontains the barrel vacuum seal, the target mount optical and $x$-ray windows, $x$-ray cassette film holder, and feedthroughs for internal electronics and sabot stripper mounts. The second part of the vacuum chamber is a two-piece cylindrical tank with vacuum pump ports and exhaust lines that is mounted on a set of rails for moving from the work area. Within the physical constraints of the first section, virtually any type of target can be mounted in the target holder. Obliquity can be changed from 0 to $65^{\circ}$ with ease. Odd target shapes can be mounted using adapter plates available at the site. 


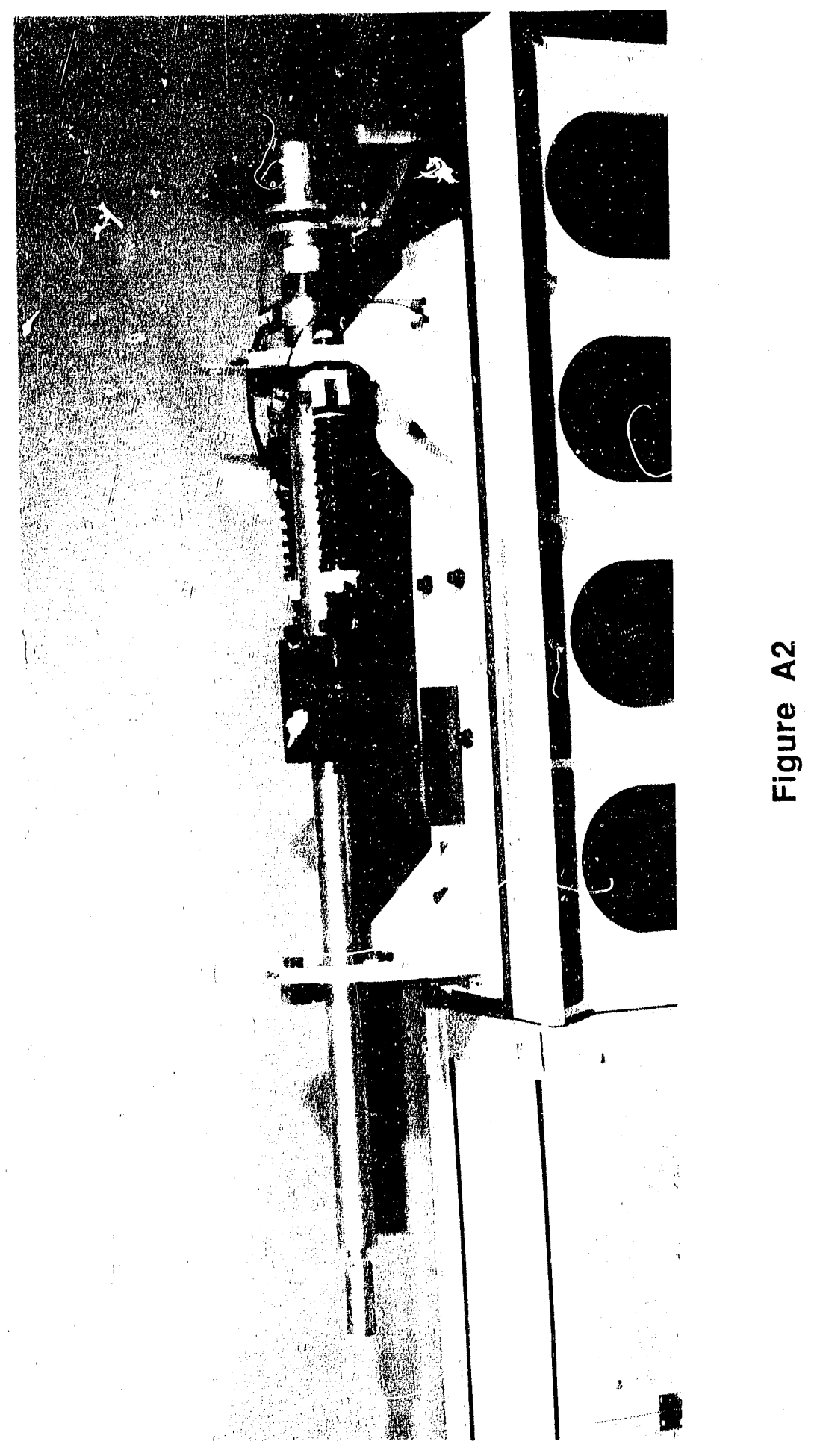




\section{Small-Gun Target-Mounting Systems}

All three small-gun systems are mounted on a single table with their bores parallel. The target mount is a massive steel structure designed to mount a single plate-type target at either 0 or $60^{\circ}$ obliquity (Fig. A3, at left). Other cylindrical-type targets can be mounted using adapter rings for the specific targets. As shown in Fig. $\mathrm{A} 3$, the sides of the mount are slotted to permit the passage of visible light from the flash lamps, eic., or $x$-rays for the $x$-ray diagnostics. The main target mount tests on a ground steel surface that facilitates the movement of the mount from one gun to another by means of air nressure floating th $\bullet$ mount, thereby making the assembly easily movable from one light gun to the next. Over the mount is a shrapnel-shield bos: corstructed of 3/8-in. steel with doors that swing up fro access. This shield is also mounted on linear va!! be:rings for movement rom one gun to another. Behind the light guns and target mount is located the catch tank, which is filled with sand and is an additional precaution against sinrapnel getting out into the cell itself. This catch tank is also mounted on wheels to move laterally from one gun to the next.

\section{Target Alignment and Target Set-Up}

All guns are equipped with an accessory mount for mounting a low-power HeNe laser for alignment of target and bore (shown in breech of .50-cal. BMG in Fig. Al, second from left). The mounts are adjustable to allow the beam to be aligned along the centerline of the bore. The aligriment tool is mounted to a modified cartridge that fits the breech exactly, thereby eliminating errors and alignment time. This alignment method ensures proper inounting of the target, sabot strippers, pin velocity traps, and pin triggers for diagnostics.

\section{Projectiles and Launch Capabilities}

Almost any material that can remain coherent in the bore can be launched. That is, it must survive the launch pressure: $i$ and, to some extent, temperatures. Some of the materials that have been launched in the past include: plastics, teflon, figerglass, lexan, nylon, and poiyethylene for sabots; aluminum through uranium for projectiles and pushers. Some projectiles have odd shapes such as cubes, spheres, and hollow rods or other geometric shapes. Most often, these shapes have to be launched using a sabot, which is a device to match the projectile to the bore diameter. Sabots generally have a cylindrical shise, and have some sort of lifling engagement rings or bore seal around the outside of the cylinder. When launching the sub-caliber ojectiles, a pusher made from steel is used to guide the sabot and projectile down the barrel.

\section{Diagnostics}

Research conducted on the guns depends primarily on three types of diagnostic tools: flash radiography, high-speed cinephotography, and shorting pins. At present we use all Field Emission/Hewlett Fackard flash $\mathrm{x}$-ray equipment. The 1/4scale gun is equipped with three each $300-\mathrm{kv}$ heads (Fig. A4) and three each 600-kV heuds, separated from three pulsers by coax cables, allowing them to be rearranged at will. The small gur.s have two each 150-kV heads (Fig. A5). They are mounted on a special quick mount to allow them to $n$. vie to alignment with the other small guns on 


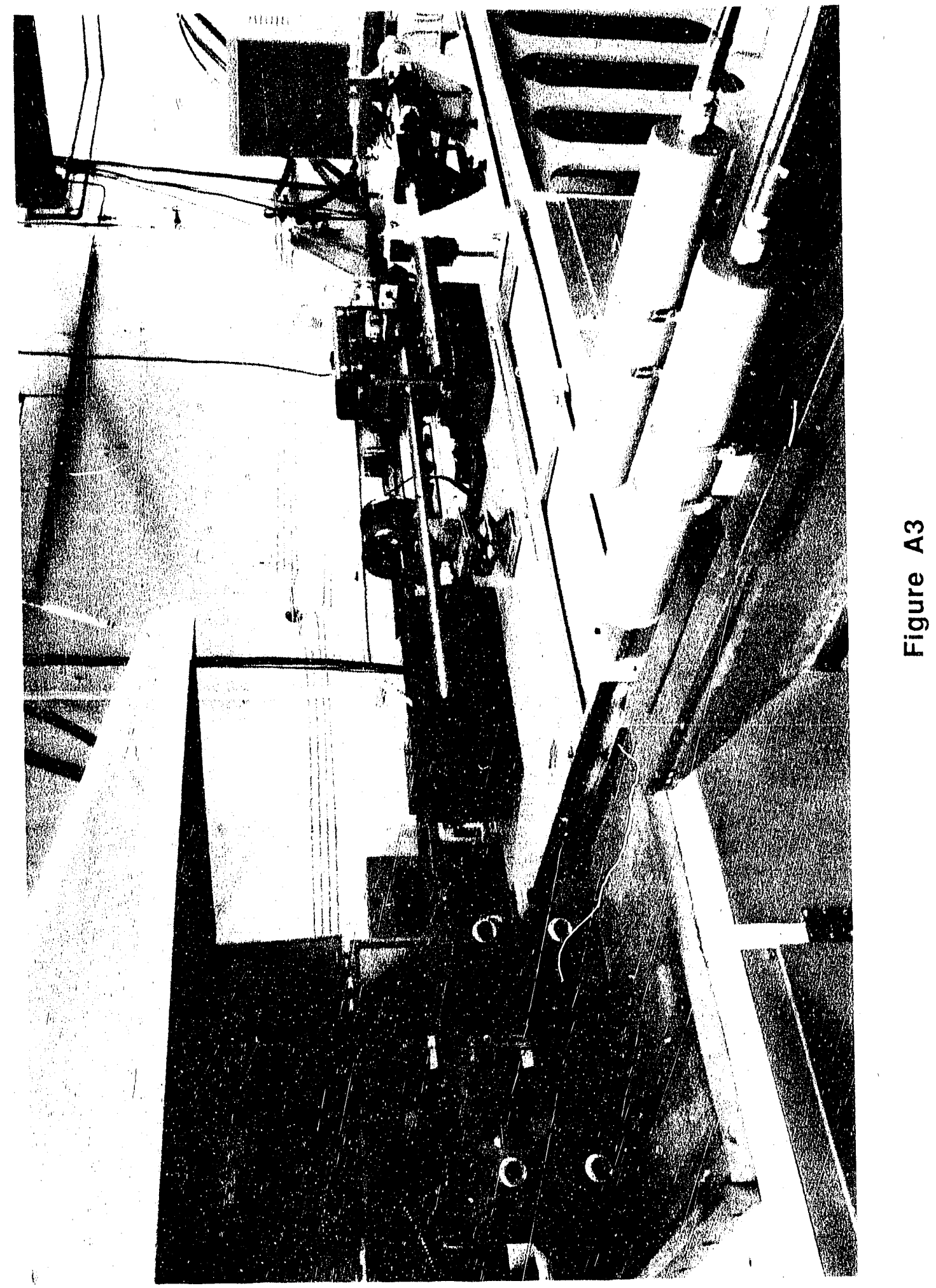



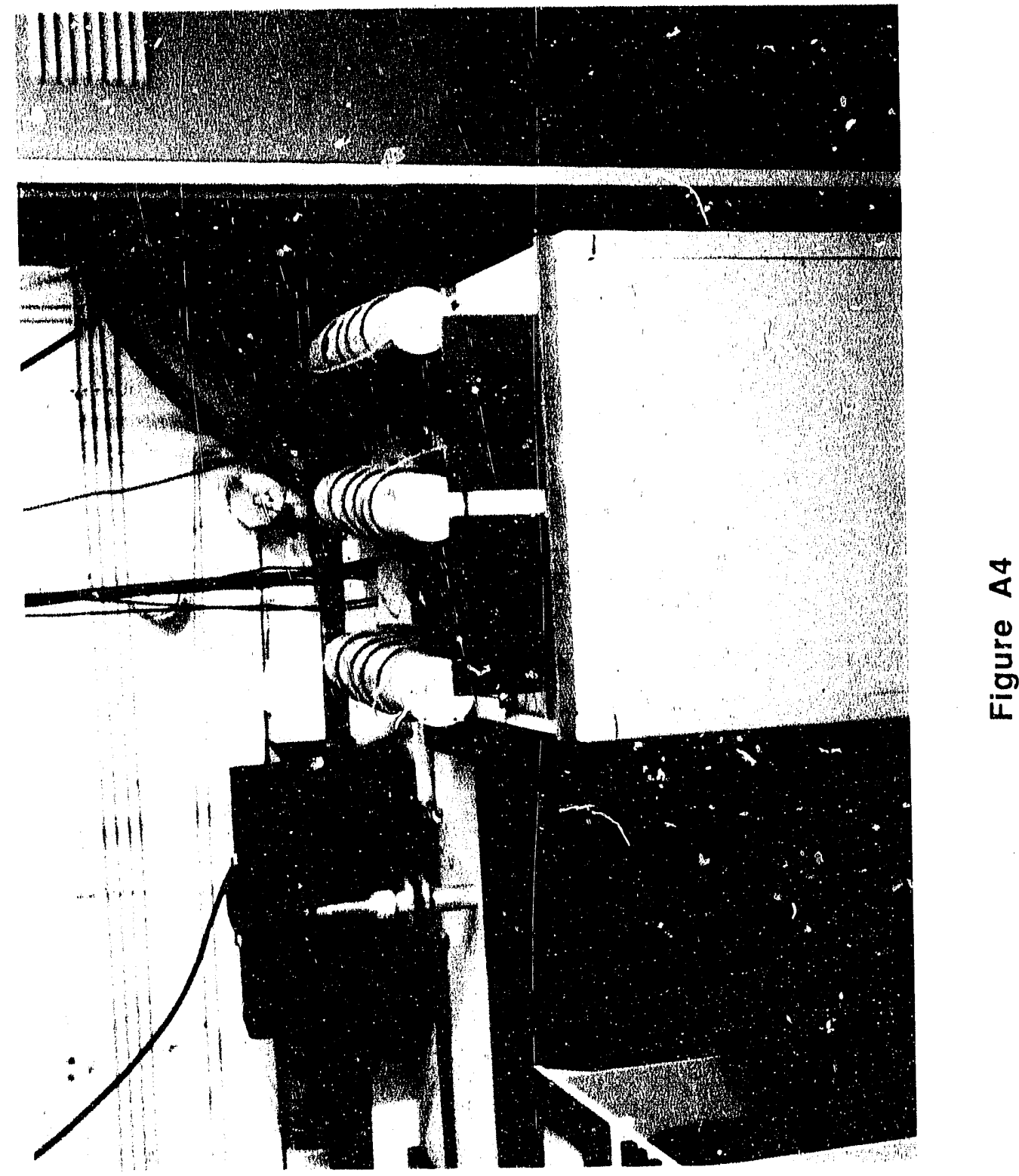


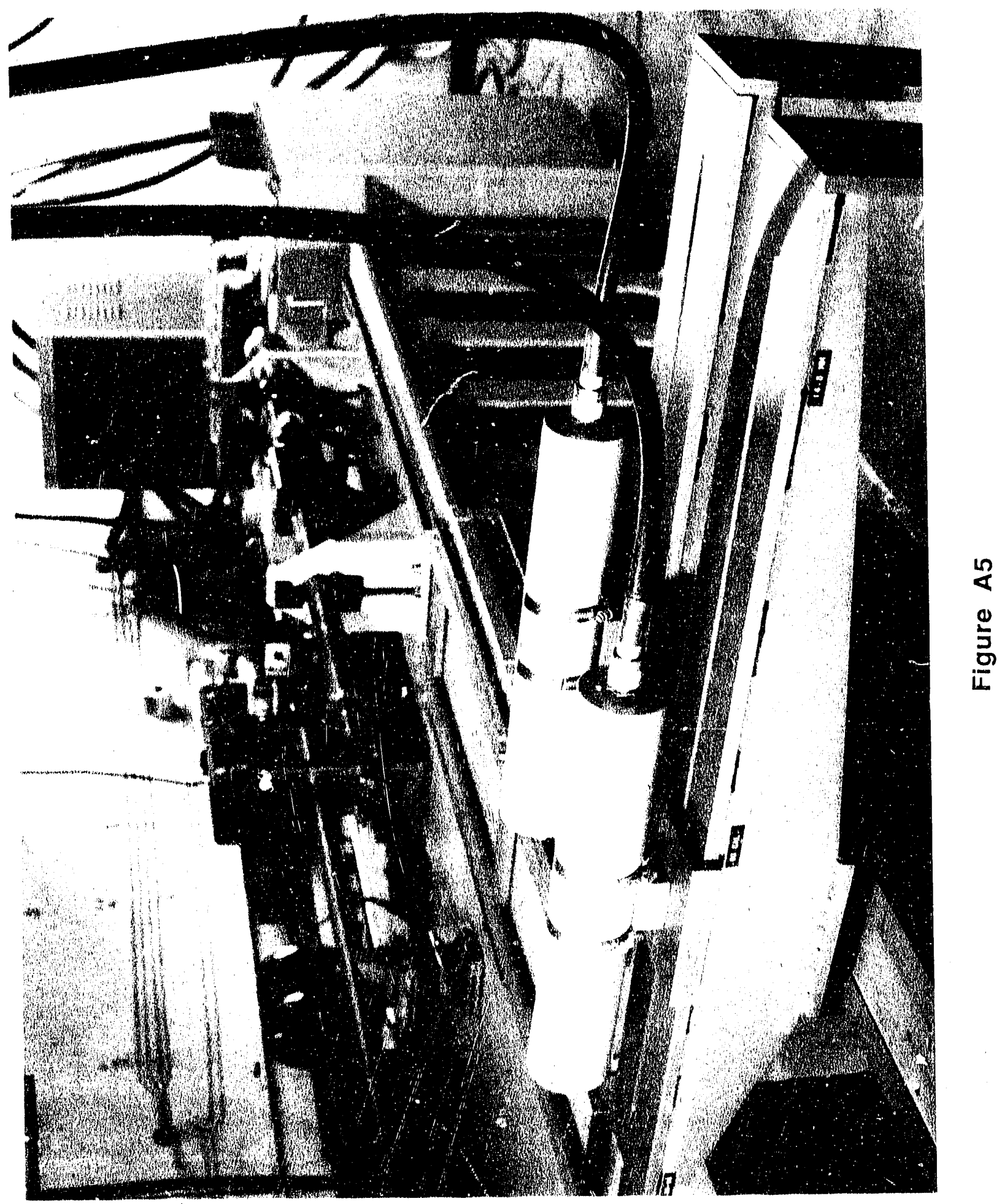


the table. All heads are fired sequentially and all are individually selectable. Velocity measurements are accurate to $\pm .5 \%$ of actual velocity. The diagnostic room adjacent to the actual guns also contains the high-speed Model camera. It is the rotating-mirror type with framing operations up to 2 million frames per second. Most ballistics events, however, use 500,000 frames per second or 2- $\mu$ s interframe time. This is important because of the limited writing time typical of this type of camera. The camera has a total of 180 frames, for a write time of $5 \times 105^{\circ}$ frames per second at $360 \mu \mathrm{s}$. Ballistic events are illuminated by a high-intensity flash lamp. In the normal operation the gun room is dark, with the shutter to the high-speed camera open. The event is recorded by running the camera up to speed, and as the gun is fired, the projectile impacts the foil shorting pin that in turn triggers the flash lamp for a film record. Obviously, there are a number of electronic circuits to ensure the proper time sequence, etc., but in the interest of simplicity the basic operation is just as described. The capacitive discharge pulse is electronically shaped to have a very quick rise time and pulse peak; therefore we can use the flashlamp not only to illuminate the event but also as an electronic shutter. The high-speed camera can be used on all the gun systems through the use of a series of turning mirrors aligned by a small HeNe laser system.

The foil pin switches are used two ways in ballistic research. The traditional way is for velocity determination by setting the foil switches a known distance apart, then using them to trigger a start-and-stop pulse that is fed into a counter (timer). The velocity is then simply determined by calculating $V-d / t$, where $d$ - distance and $t$ - time. In our facility we occasionally use foil switches on the small guns for velocity measurement. They are reasonably reliable and give repeatable results within the load curve envelope of load vs. velocity. Velocity on the 1/4-scale gun is not determined by the foil-switch method because the large gas pulse will sometimes pretrigger the counter, thereby giving erroneous velocity measurements. Foil switches are used on all gun systems for triggering other devices such as $\mathrm{x}$-rays, etc. 


\section{Figure Captions}

Fig. 1. $\quad 50$ cal FSP in $207 \mathrm{gr} \& 170$ Gr Configuration

Fig. 2 Typical blanket tesi set-up

Fig. 3. Side view of hard armor target in shot can

Fig. 4 Typical hard armor target with excursion device in place

Fig. 5 Hard armor target with C-130 floorboard mock-up

\section{Fiyure Captions Appendix A}

Fig. A1 Light gun test assembly

Fig. A2 14.55mim gun assembly

Fig. A3 Light gun assembly: target chamber

Fig. A4 $300 \mathrm{Kv} X$-ray heads

Fig. A5 $150 \mathrm{Kv} \mathrm{X}$-ray heads for light gun assembly 

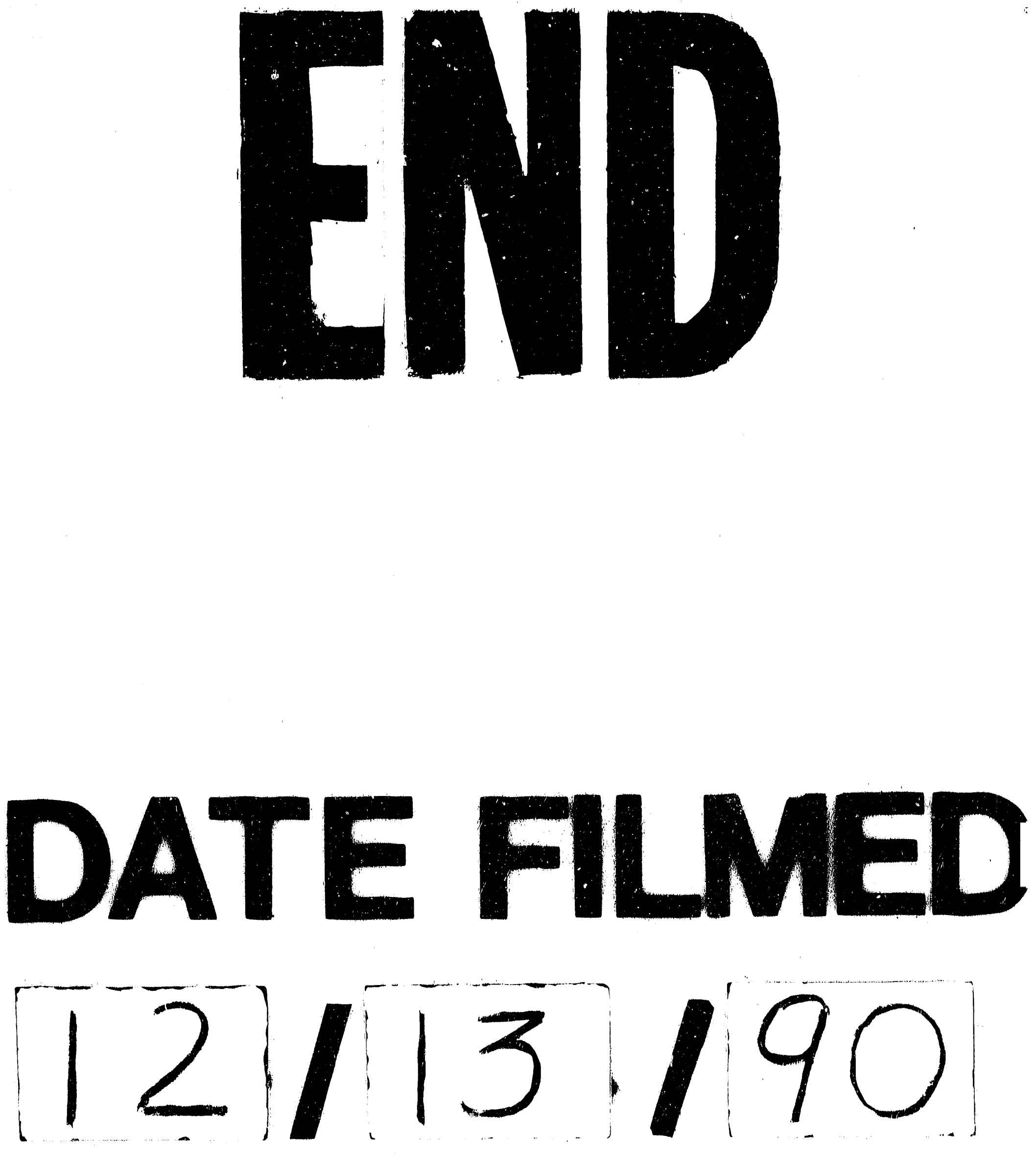
